\title{
Vorwort.
}

Fin Beitrag zu der nicht mehr spärlichen mundartlichen Literatur sind die vorliegenden L'ntersuchungen. Ihre I'nterscheidungsmerkmale von den meisten ähnlichen Darstellungen beruhen in der erstrebten phonetischen Akribie und besonders auf den in vierten Teile durchgeführten V'ergleichen mit andern Dialekten. Yor allem scheint mir die Feststellung.der Beziehungen zu den übrigen Mundarten, die, jede eimzelne mehr oder weniger, in ihrer Gesamtheit der Born sind, aus dem die hochdeutsche Gemeinsprache sich unausgesetyt verjüngen und erneuern muß, den Arbeiten über Idiome ihre Rechttertigung und ihren spezifischen Wert zu verleihen.

Gerne erfülle ich meine Pflicht, Fräulein Lehrerin Marg. Müller meines herzlichen Dankes für ihre liebenswürdige Nitwirkung an meinen Forschungen zu versichern. Hätte die Eingliederung eines weitern, schon zusammengestellten Abschnittes über Sprichwörter, geflügelte Worte usw. den vorgezeichneten Rahmen nicht erhoblich überschritten, so hätten ihre Beiträge in noch größerm Umfange verwertet werden können.

Herr Prof. Dr. Fran\% Schultz, unter dessen Auspizien die Arbeit gedieh, sei auch hier warm bedankt für sein großes Entgegenkommen, wann immer ich dessen bedurfte; desgleichen fühle ich mich Herrn Prof. Dr. Henning verpflichtet, da auch er meine Arbeit förderte. Ein Schüler beider Herren, verdanke ich ihnen viel an wissenschaftlicher Anregung und Methode. 



\section{Meinen Eltern}

dankbar zugeeignet. 
